\title{
Artigo
}

RESUMo

Inserido no projeto de pesquisa Psicanálise com crianças: teoria e clínica, financiado pela Universidade de Ribeirão Preto (UNAERP) e baseado nos pressupostos da psicanálise lacaniana, este trabalho consiste em uma pesquisa sobre a alienação e a separação, abordando suas características, importância e implicações, bem como sua possivel relação com as manifestações sintomáticas na criança. Este trabalho considera nosso momento histórico, caracterizado pelos discursos capitalista e cientifico, que corroboraram o processo de objetalização da criança. Logo, foi realizada uma reflexão acerca dos modos de alienação que operam a partir desses discursos. Em contrapartida, a Psicanálise propõe saídas que possibilitam a emergência de um sujeito.

Descritores: psicanálise; alienação; separação; clínica; contemporaneidade.

\section{A ALIENAÇÃO DA CRIANÇA: CLIINICA E CONTEMPORANEIDADE}

\author{
Thaíssa Yumi Matsuo \\ Alessandra Fernandes Carreira
}

DOl: http//dx.doi.org/10.11606/issn. 1981-1624.v20i3p475-491.

\section{Introdução}<smiles>[Z]C1=CCCCC1</smiles>

a atualidade, estamos diante das crescentes demandas endereçadas às crianças, das quais se espera um desenvolvimento rápido, uma independência precoce e um acondicionamento diante das telas hipnotizantes da tecnologia, utilizadas para liberarem os ocupados

Psicóloga. Aluna do Aprimoramento em Psicologia do Desenvolvimento na área da Saúde do Hospital das Clínicas da Faculdade de Medicina de Ribeirão Preto (HCFMRP-

USP), Ribeirão Preto, SP, Brasil.

- . Psicanalista. Membro fundador de Lalíngua - Espaço de Interlocução em Psicanálise. Professora do curso de Psicologia da Universidade de Ribeirão Preto

(UNAERP), Ribeirão Preto, SP, Brasil. 
adultos de sua função de pais. Como respostas das crianças a essas demandas, encontramos com maior frequência, dentre outras, a hiperatividade, o déficit de atenção, a agressividade e os problemas de aprendizagem. Com esses sintomas, elas obrigam seus ocupados pais a ocuparem-se delas e, por isso, lotam os consultórios, recebendo desde muito cedo prescrições de medicamentos e sendo submetidas a inúmeras técnicas de treinamento e adaptação.

A partir de uma leitura apoiada no referencial psicanalítico lacaniano, podemos dizer que esse cenário apresenta uma espécie de dimensão ampliada do desejo do Outro, que encontra-se encarnado tanto pelos pais quanto pelo entorno social. Isso funciona como correlato de uma afânise do sujeito, ou seja, é esperado que a criança não dê trabalho, não deseje fora daquilo que é dela esperado, o que pode ser correlacionado ao conceito de "alienação". Assim, pretendemos realizar neste trabalho uma pesquisa teórica abordando esse conceito, refletindo um pouco a respeito de suas características, importância e implicações para a clínica e a contemporaneidade.

A vertente clínica que motiva esta pesquisa foi o atendimento psicanalítico de uma criança, entre os três e os seis anos de idade, realizado e já concluído na Clínica de Psicologia do Núcleo Multiprofissional da Universidade de Ribeirão Preto (UNAERP). $\mathrm{O}$ atendimento desse caso foi realizado pela psicanalista Alessandra Carreira, uma das autoras desse artigo.

Nessa perspectiva, o caso conta com registros não literais das sessões, que foram utilizados como material para análise com o consentimento por escrito da família. Nesse sentido, este trabalho trará interlocuções teóricas e clínicas a partir dessa experiência, que teve duração de mais de dois anos e que vem sendo formalizada através de pesquisas e publicações há oito anos.

Trata-se do caso clínico de um menino que recebeu nesta pesquisa o nome fictício João. Adotado por Adriana (nome também fictício), ele adveio da sétima gestação de sua mãe biológica, que era andarilha e sempre entregava seus filhos para adoção. Mas, no caso de João, não se sabe o porquê, ela chegou a levá-lo consigo ao sair do hospital, período no qual não se teve notícias do menino. Quinze dias depois, porém, abandonou-o nas proximidades do hospital, desnutrido, ainda com a pulseirinha de identificação da maternidade e embrulhado em um cueiro.

A mãe adotiva, por sua vez, esperou pelo período de nove meses pela adoção de João, ou seja, aguardou justamente o período 
correspondente ao da gestação. Nesse tempo, a mãe adotiva teve uma gravidez psicológica, inclusive produzindo leite. Todavia, João recusou-se a mamar em seu seio, só aceitando o leite que ela lhe ofertava na mamadeira.

Como se pode notar, esse menino não se apresentou como o esperado desde o início. $\mathrm{Na}$ época da procura pelo tratamento, ele ainda continuava desencaixado daquilo que esperavam dele, pois estava muito agressivo, sobretudo com a mãe, e recusava-se a permanecer na escola.

Realizada essa breve contextualização sobre o caso clínico, traremos a seguir, visando prosseguir em direção aos objetivos anunciados, uma breve explanação teórica que visa introduzir o conceito de alienação.

\section{Alienação e separação}

Lacan (2003), em seu seminário sobre a identificação, aborda as operações da alienação e da separação, enfatizando a dependência do sujeito em relação à linguagem. Essas duas operações descrevem o advento do sujeito enquanto duplo efeito da falta, a partir de duas perspectivas distintas: a do ser, ou das pulsões parciais, e a do significante, que está relacionado ao grande Outro. Desse modo, a partir dessas noções, Lacan (1998, 2003) lança uma topologia a fim de dar conta da constituição do Sujeito.
Nessa perspectiva, deve-se enfatizar a importância de se considerar a premissa lacaniana segundo a qual o inconsciente está estruturado como uma linguagem, constituindo-se, portanto, como a primeira forma de apresentação do Outro. Nesse lugar se situa a cadeia significante, desvelando a alteridade presentificada na constituição do sujeito:

Uma alçada do defeito central em torno do qual gira a dialética do advento do sujeito a seu próprio ser em relação ao Outro - pelo fato de que o sujeito depende do significante e de que o significante está primeiro no campo do Outro. (Lacan, 1998, p. 194-195).

Segundo Lacan (1998), a alienação é um processo essencial à constituição do ser falante. Desse modo, o Outro, lugar geralmente ocupado a princípio pela mãe para a criança, é quem irá nomear esse bebê: o que ele sente, o que deve estar pensando, seus desconfortos etc. Portanto, há uma sucessão de fonemas elegidos para representá-lo, cuja significação caberá ao bebê decifrar. Assim, o bebê humano, desde o início de sua constituição, está marcado pela alteridade, é o Outro que lhe inserirá na civilização, que o humanizará na linguagem e lhe transmitirá um desejo.

Portanto, é fundamental que ocorra a alienação, pois é por meio das palavras e do desejo de um outro que o bebê poderá ter existência simbólica. Ou seja, a subjetividade, segundo a psicanálise lacaniana, pode ser compreendida como um aspecto 
central e organizador do desenvolvimento (Levin, 2007), o que ocorrerá essencialmente através da inserção do bebê na linguagem e na cultura.

Desse modo, o bebê se aliena na imagem de um outro, acompanhada pelos significantes do Outro, nos quais seu desejo configura-se como um "ser desejado pelo Outro”. Nesse sentido, o desejo é articulado através da demanda que provém do Outro, explicitando-se na enunciação dos significantes: "A demanda é, portanto aquilo que se anuncia na cadeia de significantes, onde se articula o desejo como efeito metonímico, na medida em que este passa de um para outro significante rolando como um dado lançado na fala" (Quinet, 2000, p. 96).

Isso instaura uma relação dual, especular, imaginária, denominada por Lacan como estádio do espelho, no qual a criança apresenta uma dependência total na sua demanda pelo amor da mãe (Rosenberg, 2002). Logo, quando o bebê começa a falar, "é como outro que ele se refere primeiramente a si mesmo... 'ele quer', 'o nenê vai...”' (Bernardino, 2006, p. 25). Nessa perspectiva, a criança, antes mesmo de seu nascimento, está marcada pelos desejos, expectativas, frustrações que se configuram no mito familiar. Quanto a isso, Siquier e Salzberg (2002, p. 85) afirmam: "A criança nasce antes para a linguagem do que para a vida". Portanto, para Lacan (1998), o sujeito é efeito do significante, sendo que é por meio da entrada na linguagem que ocorre a circulação da cadeia de significantes entre o sujeito e o Outro: "Se o pegamos em seu nascimento no campo do Outro, 
a característica do sujeito do inconsciente é de estar, sob o significante que devolve suas redes, suas cadeias e sua história, num lugar indeterminado" (p. 198).

Logo, é preciso que o Outro atribua uma significação ao grito do filhote humano, transformando a necessidade supostamente expressa no grito em uma demanda. Assim, antes mesmo de darmos continuidade à compreensão dos aspectos relativos ao processo de alienação, faz-se importante estabelecer uma distinção sucinta entre os conceitos de demanda e necessidade.

A necessidade não pressupõe o Outro, trata-se antes de uma relação linear, pois pressupõe a existência de um objeto que satisfaz sempre, por isso aproxima-se, por exemplo, dos animais que podem encontrar seus objetos na natureza, enquanto a demanda abarca essencialmente a dimensão dos seres falantes, intermediada pela linguagem e sua cadeia de significantes: "Há um Outro que fala através de mim fazendo-me tropeçar nas palavras e dizer coisas que não tinha a intenção de dizer" (Quinet, 2000, p. 89).

Enfim, de modo sintético, destaca-se que a fala pressupõe e faz surgir a alteridade. Nesse sentido, a demanda não visa a um objeto, diferentemente da necessidade, mas primordialmente a demanda é dirigida a um Outro, trata-se de um apelo, de toda a cadeia de significantes que é dirigida ao Outro. Logo, pode-se inferir que toda fala é uma demanda.

A demanda, como demanda do Outro, desvela que no homem o desenvolvimento não ocorre naturalmente por meio de fases, mas antes está calcado nas intervenções da demanda do Outro no circuito pulsional do bebê, como a passagem da pulsão oral à pulsão anal (Jerusalinsky, 2010). Não há um processo de maturação libidinal, mas uma relação a dois, na qual o sujeito se encontra em disjunção e conjunção com a demanda do Outro (Quinet, 2000).

Nesse sentido, quando o bebê grita, a mãe supõe um pedido, que é interpretado como uma demanda por satisfação dirigida a ela. A demanda pode ser entendida como um apelo na busca por complementação através de um objeto que poderia satisfazer o sujeito. $\mathrm{Na}$ demanda fica implícito o desejo na busca pelo objeto perdido:

$\mathrm{Na}$ demanda há sempre um pedido de restituição de um status quo ante, de um estado anterior de complementação que o sujeito supõe existir ou ter existido.... O desejo é justamente a busca, a procura daquele objeto suposto da primeira experiência fictícia de satisfação, que nunca existiu, mas é um postulado necessário a Freud para constituir o objeto como faltante e sua conseqüente busca por parte do sujeito. (Quinet, 2000, p. 88). 
Nesse sentido, o sujeito se estrutura a partir de um furo, o qual é correlato ao conceito do objeto perdido, como citado acima. Logo, é condição necessária ao desejo a introdução da dimensão da falta, portanto, o desejo é por definição sempre insatisfeito e incompleto.

É interessante destacar que Lacan (1998), em seu seminário sobre os quatro conceitos fundamentais da psicanálise, vale-se do mito de Aristófanes, o qual de modo sintético traz uma representação mítica pela busca por um complemento sexual na procura pelo amor. Lacan (1998) faz uma releitura desse mito, e propõe a partir da experiência analítica uma busca pela parte perdida em si mesmo, "que é constituída pelo fato dele ser apenas um vivo sexuado, e não mais ser imortal" (p. 195). Vemos que Lacan retoma esse mito para encarnar a parte faltosa, a qual é essencial para o engendramento do sujeito.

Desse modo, Lacan denomina como vel, referindo-se a essa primeira operação essencial em que se funda o sujeito: a alienação. Trata-se do que "condena o sujeito a só aparecer nessa divisão que venho, me parece, de articular suficientemente ao dizer que se ele aparece de um lado como sentido, produzido pelo significante, do outro ele aparece como afânise" (Lacan, 1998, p. 199).

Nessa perspectiva, trata-se de uma relação fundamental entre o sujeito e sua relação com o desejo do Outro, apontando para a sua posição nesse interjogo movido pela falta. $\mathrm{O}$ "objeto a" assume uma posição relevante quanto à posição do sujeito em relação ao desejo do Outro, pois ele emergiria supostamente como o objeto que o Outro demanda ao sujeito a fim de completá-lo. Trata-se, segundo Carreira (2009a, p.164), do objeto que quitaria a dívida da linguagem, considerando-se que "alguma coisa tem que ser paga àquele que introduz seu signo"

Todavia, a admissão do "objeto a" ao atender a essa demanda do Outro implicaria no eclipse do sujeito, ou seja, "nessa operação o resultado é um composto, um Outro completo, que incorpora o objeto e anula o sujeito, configurando-se assim um 'nem sujeito nem objeto"' (Carreira, 2009a, p. 164). A partir dessas considerações, pode-se depreender que implícita a essa noção do vel opera-se uma relação marcada pela impossibilidade, independentemente da escolha que se faça; há por consequência "um nem um, nem outro" (Lacan, 1998, p. 200). Pensando nessa questão, Lacan a exemplifica por meio da metáfora da bolsa ou a vida: se escolho a bolsa, perco ambas; se escolho a vida, tenho a vida sem a bolsa, ou seja, uma vida decepada na qual algo é perdido (Lacan, 1998).

Dessa divisão, abre-se a possibilidade para a segunda operação descrita por Lacan (1998): a separação, que determina o término da circularidade da relação do sujeito com o Outro, encontrando-se, portanto, na hiância. 
Nesse sentido, é a partir desses intervalos que cortam os significantes que o desejo do Outro é apreendido pelo sujeito naquilo que não cola, nas faltas do discurso do Outro que também é barrado. É justamente nesse furo que se desvela a dimensão do desejo que permitirá ao sujeito separar-se do Outro. O desejo, portanto, pode ser compreendido como uma defesa contra a demanda do Outro.

Lacan (1998) aponta que na separação coexistem duas faltas: a do sujeito e a do Outro. É na intersecção dessa falta presentificada entre o sujeito e o Outro que se encontra o vazio, que será ocupado pelo "objeto a" - o objeto perdido, causa de desejo. Nesse sentido, separare, separar, trata-se do movimento de engendrar-se, de pôr no mundo, assumindo-se enquanto um sujeito faltoso, portanto, desejante.

Após essa breve retomada teórica sobre a separação e a alienação e suas principais implicações, segue-se a apresentação de vinhetas do caso clínico, que serão importantes para ilustrar a questão da alienação, possibilitando suporte para uma reflexão, ainda que inicial, no âmbito clínico e contemporâneo.

\section{O caso clínico}

A partir destas considerações teóricas, pode-se observar a alienação através da análise de vinhetas do caso clínico, nas quais a criança se apresentou capturada e identificada ao olhar materno. Neste sentido, destacam-se alguns excertos das entrevistas preliminares realizadas com Adriana e das intervenções efetuadas pela analista:

Adriana: - "É. Meu marido grita com ele, mas diz que só eu grito".

Analista: - "O que é que isto tem a ver com o espelho?".

Adriana: - "Ah... En grito e ele faz".

(terceira sessão de entrevista com a mãe)

Adriana: - “... quando eu estou tranquila ele tá, quando eu estou agitada ele tá, ele corre. Acho que a correria do meu marido passou para mim e eu passei para ele". Analista: - "Você tenta atender o seu marido e o João atende você".

(quinta sessão de entrevista com a mãe)

Acrescenta-se que a mãe permanecia com a criança assiduamente, enquanto o pai aparecia esporadicamente, aos finais de semana, pois era viajante. Aparentemente essa relação dual entre mãe e filho 
mostrou-se excessiva ao ponto de o filho não tolerar a ausência da mãe quando esta ia ao banheiro. Segundo a mãe, nessas circunstâncias, João chorava e batia na porta e, desse modo, conseguia ser atendido por ela. Adriana, inicialmente, atribuiu esse comportamento ao medo possivelmente decorrente das condições de sua adoção.

Todavia, considerando-se que os processos de alienação e separação oscilam e são dinâmicos, concomitantemente, foi possível identificar movimentos e tentativas de separação, de desvencilhar-se desse outro, como pode ser observado nas respectivas passagens:

Adriana: - “... Eu prendi a cachorra, ele pegava a chave e queria soltar a cachorra”. (segunda sessão)

Adriana: - “... Ontem ele jogon o meu sabonete fora”.

(terceira sessão de entrevista com a mãe)

Neste sentido, o surgimento do sujeito, que é o que permite que ele saia da alienação, que se separe, encontra-se na dimensão da experiência da falta. É esta que permitirá o advento do sujeito do desejo, com uma existência simbólica própria. Ou seja, é ao dar-se conta que o Outro não é tão absoluto, que algo lhe falta, escapa, que o filhote humano começará a se perguntar sobre o seu próprio desejo, "produzindo um descolamento: de se parare vai se parere, ou seja, parir-se, engendrar-se." (Bernardino, 2006, p. 26).

Nesta perspectiva, destaca-se a seguinte intervenção realizada pela analista, a partir da qual se pode considerar ter havido a implicação da mãe no tratamento da criança; afinal, ela chegou à conclusão que já era hora de "sair da barra da saia":

Analista: - "Mas ele sempre vai ter você?".

Adriana: - "Não. Tem momentos que ele vai ficar sozinho".

Analista: - "Como João vai lidar com a separação que já aconteceu, se ele está ligado na barra da saia".

Adriana: - "Eu grudei demais. Talvez seja a hora de desgrudar um pouco". (quinta sessão de entrevista com a mãe)

Posteriormente, no decorrer das sessões, João comunicou à analista, por meio de representações e cenas lúdicas, sobre a necessidade de estabelecer limites e assim sair desse lugar imaginário e mortífero de ser para sempre o objeto do desejo da mãe (Rosenberg, 2002). Para tanto, ele pegou uma tesoura sem corte e a colocou entre os dedos, tentando com isso cortar alguns soldadinhos de plástico, ao que a

482 Estilos clin., São Paulo, v. 20, n. 3, set./dez. 2015, 475-491. 
analista lhe pontuou:Analista: - "Você

está tentando separar os dois?”. (segunda sessão com a criança)

Nessa perspectiva, inúmeros movimentos envolvendo a alienação e a separação foram observados ao longo do tratamento da criança. Em uma brincadeira com a massa de modelar, por exemplo, pegou todas as cores e as amassou juntas, fazendo um bolo. Depois tentou separá-las, cortando-as com a tesoura, voltando em seguida a grudar as partes e fazer uma coisa só. Ainda nos atendimentos iniciais, a criança reproduziu frequentemente jogos de ocultação e alternância, nos quais brincava de entrar e sair da sala de atendimento. Enfim, alternava-se em presença e ausência diante do Outro, representado pela analista na transferência.

Destaca-se a presença da figura do guarda como um aspecto significativo do tratamento. Ele sempre ficava na porta da clínica, demarcando um lugar entre o dentro e o fora, estabelecendo, desse modo, um limite. A criança, em um determinado momento, com o consentimento da analista, passou a levar os brinquedos da sessão para casa, desde que cumprisse a seguinte condição: deveria devolver um, para só depois poder pegar outro. Desse modo, em uma das sessões a criança esqueceu o brinquedo no carro. Nessa ocasião, a analista propôs que a criança pegasse o brinquedo e, ao final da sessão, o devolvesse ao guarda. Tal intervenção da analista fez com que o guarda passasse a representar de 
modo mais consistente uma borda para a criança, como pode ser exemplificado pela função reguladora que este passou a assumir.

Nesse contexto, pode-se afirmar que a figura do guarda foi importante para a sustentação de uma lei, por meio da troca de brinquedos que a criança estabeleceu com ele. Logo, a interdição paterna e a entrada na linguagem possibilitam à criança sair do lugar na qual é falada, o que pode favorecer sua separação dessa demanda: “a entrada do pai destitui este lugar imaginário onde a criança é o falo da mãe, permitindo ao infans sair desse lugar mortífero (de ser para sempre o desejo do desejo da mãe), para se constituir como um sujeito desejante" (Rosenberg, 2002, p. 62-63).

Ainda no que se refere à saída deste lugar junto ao desejo do Outro, a seguinte vinheta traz uma intervenção da analista em uma cena em que João estava ordenando que a mãe recolhesse as coisas dele que estavam no chão, tal qual como uma mãe faz.

Analista: "Parece que a sua mãe não quer o que você quer". (terceira sessão com a criança)

Por meio desse excerto da sessão clínica, pode-se inferir que a criança estava se colocando na posição da mãe, confundindo-se com esta, tomando-lhe o próprio lugar ao estabelecer o que esta deveria ou não fazer. Nessa perspectiva, a pontuação da analista foi importante na medida em que sugeriu uma demarcação do desejo para além do desejo materno, o que possivelmente favoreceu a abertura para uma saída. Nesse sentido, segundo Soler (1997, citado por Pisetta \& Besset, 2011): “a separação supõe uma vontade de sair, uma vontade de saber o que se é para além daquilo que o Outro possa dizer, para além daquilo inscrito no Outro” (p. 321).

Portanto, a separação determina o término da circularidade da relação do sujeito com o Outro. Encontra-se, portanto, na hiância, a qual inicialmente não estava ocorrendo devido ao excesso de presença da mãe.

No que se refere a esta ausência de intervalos do sujeito em sua relação com o Outro, pode-se citar que, próximo ao fim do tratamento, João recusa-se a comparecer à sessão, pois sua mãe o havia impedido de trazer sua cachorrinha, com a qual estava muito preocupado, receando que esta morresse assim como acontecera com seu outro cachorro e seus peixinhos. Ele culpou a mãe pela morte 
destes últimos. Neste sentido, a mãe veio no lugar dele e disse que precisava colocar mais limites para João, o que não o fazia por dó. Além disso, afirmou:

Adriana: "Eu mato a vontade dele?".

O significante "mato" aparece em uma cadeia que remete tanto à preocupação de João com a morte quanto ao desejo dele, o qual a mãe tentava matar. Mas, se o desejo é morto, em que condição fica o sujeito? Como ele poderia existir enquanto sujeito se só há espaço para o saber do Outro?

Nesse sentido, a separação só poderá ser concebida a partir da falta. Esta, segundo Lacan (1998), encontra-se tanto no campo do sujeito como no campo do Outro:

O inconsciente se funda nessa hiância, é a ela que os significantes fazem borda. É esse vazio que o tecido significante visa tamponar, e é por ele que o desejo advém. Desejo que possibilita ir além da alienação significante, ir além do enunciado ditado pelo Outro. (Sirelli, 2010, p. 66).

Portanto, a partir da análise do material clínico, pode-se dizer que os manejos da analista, a implicação materna, a inserção da lei e o próprio desejo do sujeito de se separar foram condições que favoreceram a separação em relação à demanda do Outro.

João pôde encontrar um analista muito cedo, antes de ser medicado, o que é raro no mundo contemporâneo. Através de seu percurso, podemos ver uma outra saída para o sujeito que não as garras do tecnicismo. Isso permite dizer que em alguns aspectos ele separou-se não somente do desejo de Adriana, mas também, por ter sustentado sua análise, do desejo dos discursos científico e capitalista. Pensando nessas condições, segue-se a ampliação dessas questões, com ênfase para alguns apontamentos sobre a alienação da criança no discurso contemporâneo.

\section{Questões contemporâneas}

Especificamente no que se refere à alienação, não podemos desprezar o momento histórico que vivemos. Nessa perspectiva, a literatura - por exemplo, Kupfer e Bernardino (2009) - tem apontado em nossa civilização contemporânea o declínio do Nome-do-Pai que traz, dentre os seus efeitos, a tendência à objetalização do sujeito, proveniente do embricamento entre a ciência e o capital.

Tal objetalização pode ser identificada na não responsabilização quanto ao modo de gozo de cada um, uma vez que a responsabilidade é colocada nas condições sócio-históricas ou nas patologias. Trata-se, segundo Lacan (1969/2003, 
p. 360, citado por Barroso, 2010, p. 3), do "problema mais intenso de nossa época, na medida em que ela foi a primeira a sentir o novo questionamento de todas as estruturas sociais pelo progresso da ciência".

Segundo Lacan (1969, 1970, citado por Barroso, 2010), a ascensão social daquilo que Lacan chamou de objeto mais-de-gozar está relacionada à autoridade exercida pela ciência, que fortalece e corrobora a disseminação do discurso do mestre, na qual impera a necessidade do mais-de-gozar para que a máquina funcione. Concomitantemente, ocorre o enfraquecimento da função paterna, ou seja, do "ao menos um" fundamental à transmissão da castração. Desse modo, a criança tem sido colocada na posição desse compensador do "menos um" do gozo materno, o que, correlato da desautorização paterna, engendra o processo de objetalização desta.

Há uma ausência da mediação, ou mesmo interdição, realizada pela função do pai, o que deixa a criança exposta e suscetível a todas as capturas fantasmáticas, inclusive às da ciência. Ela é tomada como objeto, ou seja, está alienada às teorias e técnicas criadas para contê-la enquanto sujeito. Trata-se, portanto, de algo compatível a uma identificação ao traço que o objeto materno atribui à criança (Bruder \& Brauer, 2007).

A despeito das interferências culturais e econômicas de nossa época, é pertinente assinalar igualmente que o sujeito, segundo a Psicanálise, se posiciona de forma eletiva perante o Outro. Desse modo, o sintoma da criança para a Psicanálise pode ser compreendido como uma tentativa de separar-se, ou seja, a manifestação do sintoma na criança pode apontar para a presença de um ser desejante. Logo, a emergência do sintoma ocorre como uma maneira de proteção contra a alienação no ideal dos pais (Prestes, 2005). Até que ponto essa função do sintoma da criança também não serviria como resistência à alienação também em voga no discurso contemporâneo?

Em relação ao caso clínico estudado neste trabalho, é interessante observar essa tentativa de separação que a criança lança constantemente, buscando desvencilhar-se do desejo do Outro. $\mathrm{Na}$ seguinte vinheta clínica, relatada pela analista, podemos localizar a emergência do sujeito: "Ele retorna. Passa a tinta vermelha por cima da azul e me mostra que o roxo apareceu. Digo que juntando duas cores diferentes nasce uma terceira. Arremato: 'O que mais nasce se dois diferentes se juntam?'. 'O menino" (Carreira, comunicação pessoal, 2004, p. 04). 
Lacan foi o primeiro a estabelecer uma relação entre o inconsciente da criança e o desejo parental, ou seja, como o discurso parental se inscreve e se significa para o sujeito. Neste caso, especificamente, a busca pelo tratamento ocorreu por causa da agressividade de João e de sua aversão pela escola, esta última inconcebível em uma sociedade que transformou essa instituição em mais do que um direito, isto é, transformou-a em um dever para todos.

Nesse sentido, podemos compreender a emergência do sintoma, segundo a Psicanálise, como um representante da verdade, pertencente ao campo do simbólico, ou seja, ele está articulado à história particular do sujeito: “... a história singular de um sujeito se urde com a história dos outros que o constituem, mediadores e suportes de uma história coletiva-social e cultural- que deixa as suas marcas." (Segal, 2002, p. 16)

Contrariamente à visão médico-científica, o sintoma para a Psicanálise não é entendido como uma doença, mas como algo que pode ser decifrável e, portanto, analisável. Como propõe Lacan, o inconsciente é estruturado como uma linguagem; desse modo, ao reler Freud, postula o sintoma como uma metáfora, à medida que condensa uma série de sobredeterminações em cadeias. Nesse sentido, a decifração do sintoma permite que se chegue à verdade do sujeito, a qual é desconhecida por ele próprio.
Conclui-se que a Psicanálise intervém como um instrumento que permite saídas possíveis para que o sujeito se posicione. A dimensão ética da psicanálise implica na responsabilização do sujeito na escolha de sua neurose, o que caminha em uma direção oposta àquela visada pela ciência, em aliança com o discurso capitalista. Deste modo, o ato psicanalítico “... refere-se ao trabalho possível com o inconsciente de cada um na sua singularidade, fundado e fundante na interioridade de um aparelho psíquico que tomou como próprio aquilo que lhe foi oferecido como alheio". (Segal, 2002, p.43)

Em contrapartida, os discursos capitalista e científico apresentam uma proposta similar ao Mito de Aristófanes, citado no décimo primeiro seminário de Lacan (1998). Eles tamponam a dimensão da falta, sustentando que é possível atingir-se a completude por meio de uma complementação que somente o mercado de consumo ou o conhecimento científico poderiam oferecer ao sujeito.

Esse processo de tamponamento da falta na modernidade se opera por meio da ciência, a qual surge enquanto detentora de um saber através do discurso do mestre, o qual provoca um assujeitamento ao outro: "Alienado ao desejo do Outro, o sujeito con(some): desaparece como sujeito e se molda como objeto para atender à suposta demanda do Outro" (Carreira, 2009b, p. 129).

Por outro lado, a ascensão social do objeto mais-de-gozar está 
relacionada à autoridade exercida pela ciência, cujo discurso não deixa nenhum lugar para o homem (Alberti \& Elia, 2008). Já no capitalismo, o ato de consumir passa a representar a única forma de se fazer escolher, de se posicionar. Ou seja, paradoxalmente à proposta da Psicanálise, o discurso capitalista e científico propõe uma única saída: a alienação.

Especificamente, o discurso capitalista, a partir da perspectiva do consumo, possibilitou uma constante replicação de desejos, possibilitando uma ressignificação das mercadorias, que assumiram o estatuto de símbolos, signos e do próprio desejo em si, que acenderam como uma nova modalidade do comprar. Como afirma Bauman (2001):

o espírito movens da atividade consumista não é mais o conjunto mensurável de necessidades articuladas, mas o desejo-entidade muito mais volátil e efêmera, evasiva e caprichosa... o desejo tem a si mesmo como um objeto constante, e por esta razão está fadado a permanecer insaciável. (p. 88).

Concomitantemente, com o advento do capitalismo observamos os excessos característicos das sociedades modernas, que podem ser encontrados no cotidiano através dos hipermercados, dos hipermodelos, da hipervaidade, da hiperescolha (Feijoo, 2010) e (por que não?) da hiperatividade. Ironicamente, esse efeito de exacerbação proposto pelo capitalismo parece querer nos induzir à ilusão de uma pluralidade de possibilidades, quando, na verdade, apresenta apenas uma única saída para o sujeito: a alienação. Desse modo, replicam-se os desejos, os quais devem ser preenchidos com o ato de consumir.

Portanto, o mercado apropriou-se dos preceitos de liberdade e autonomia ao não cessar de nos oferecer cada vez mais prazer através da oferta de objetos a serem consumidos, sugerindo-nos que consumir é exercer o direito de escolher, sendo considerado como a expressão da capacidade de mostrar seu próprio valor de uso, enquanto mercadoria (Szapiro \& Resende, 2010).

Podemos dizer que o discurso científico, prestando serviços ao capitalismo, impera diante dos pais. Eles foram destituídos por esse discurso de seu lugar de saber a respeito do lugar da criança no desejo, o que traz efeitos significativos na relação com seus filhos. Os pais estão desistindo de sustentar suas próprias paternidade e maternidade, quando, na verdade, são os filhos que devem separar-se de seus pais (Freud,1909/1996; Strauss, 2000).

488 Estilos clin., São Paulo, v. 20, n. 3, set./dez. 2015, 475-491. 


\title{
Considerações finais
}

Seja por meio da exposição do caso clínico, seja através das questões teóricas aqui abordadas, há algo de transversal: a afânise do sujeito. Essa condição pode ser impelida ou mesmo exacerbada nestes tempos modernos. É preocupante, portanto, a condição na qual as crianças se encontram, justamente por ocuparem um lugar de vulnerabilidade em relação ao discurso da ciência que, a serviço do capitalismo, patologiza a infância e oferece aos pais um tecnicismo a ser posto no lugar de seu desejo.

Além dos pais, as instituições para as crianças, de um modo geral, parecem estar cada vez mais tecnicizadas e intolerantes às queixas infantis: não há uma escuta, mas uma desresponsabilização, uma escolha por medicalizar. Os sintomas, o diagnóstico, a patologia são aspectos que supostamente justificariam um determinado repertório comportamental, tornando-o mais "aceitável”, se assim podemos dizê-lo, mais tolerável ou ainda preocupante.

$\mathrm{Na}$ ficção científica Admirável mundo novo, Aldous Huxley (1980) traz a ideia da produção em série do ser humano: um único óvulo seria capaz de originar 96 gêmeos, processo denominado como Bokanovsky (Huxley, 1932, citado por Santos, Amorim Neto, \& Goes). Desse modo, as pessoas e toda a comunidade são padronizadas, pois todos têm a mesma gênese. De modo análogo à ficção, o ato de medicalizar e a submissão a técnicas de controle e treinamento das crianças parece ter como subsídio estruturante a noção de um denominador comum a todos, de modo que se pode enquadrar, categorizar e generalizar as queixas e sintomas.

Mas que lugar o sujeito pode ocupar nisso tudo? Como diria João, o lugar daquele que vai cuidar para que o sujeito não morra.

THE CHILDREN'S ALIENATION: PRACTICE AND CONTEMPORARY LIFE

\begin{abstract}
Inserted in the research project Psychoanalysis with children: theory and practice, funded by the University of Ribeirão Preto (UNAERP, in the Portuguese acronym) and based on the assumptions of Lacanian psychoanalysis, this work. consists in a research about alienation and separation, discussing its characteristics, importance and implications, as well as its possible relation with symptomatic manifestations in children. This project considers our historical moment, characterized by the capitalist and scientific discourses, which contributed to the process of the child objectivization. Therefore, a reflection about the modes of alienation that operate from these speeches was performed. In contrast, psychoanalysis proposes solutions that enable the emergence of the subject.
\end{abstract}

Index terms: psychoanalysis; alienation; separation; practice; contemporary life. 
LA ALIENACIÓN DEL NIÑO: CLÍNICA Y CONTEMPORANEIDAD

\section{Resumen}

Insertado en el proyecto de investigación "El psicoanálisis con niños: teoría y práctica", financiado por UNAERP y con base en los supuestos del psicoanálisis lacaniano, este estudio pretende investigar la alienación y la separación, presentando sus características, importancia y consecuencias, asi como su posible relación con las manifestaciones sintomáticas en niños. En este trabajo se consideró nuestro momento bistórico, caracterizado por los discursos capitalista y científico, que corroboran el proceso de objetalización de los niños. Por lo tanto, se realizó una reflexión acerca de los modos de alienación que operan dichos discursos. En cambio, el psicoanálisis propone salidas que permiten la emergencia de un sujeto.

Palabras clave: psicoanálisis; alienación; separación; práctica; contemporaneidad.

\section{REFERÊNCIAS}

Alberti, S., \& Elia, L. (2008). Psicanálise e ciência: o encontro dos discursos. Revista Mal-Estar e Subjetividade, 8(3), 779-802.

Barroso, S. F. (2010). A criança, de Freud a Lacan: do ideal ao objeto. Revista eletrônica do Instituto de Psicanálise e Saúde Mental de Minas Gerais - Almanaque On-line, 4(7), 1-12. Recuperado de http://www.institutopsicanalise-mg.com.br/psicanalise/ almanaque/07/Textos/Suzana.pdf

Bauman, Z. (2001). Modernidade líquida. Rio de Janeiro, RJ: Jorge Zahar.

Bernardino, L. M. F. (2006). A abordagem psicanalítica do desenvolvimento infantil e suas vicissitudes. In L. M. F. Bernardino (Org.), O que a psicanálise pode ensinar sobre a criança, sujeito em constituição (pp. 19-41). São Paulo, SP: Escuta.

Bruder, M. C. R., \& Brauer, J. F. (2007). A constituição do sujeito na psicanálise lacaniana: impasses na separação. Psicologia em Estudo, 12(3), 513-521. doi: http://dx.doi. org/10.1590/S1413-73722007000300008
Carreira, A. F. (2004). Homem(lete). Caso clínico. In I Seminário Clínico, Ribeirão Preto, SP.

Carreira, A. F. (2009a). Algumas consideraçôes sobre a fantasia em Freud e Lacan. Revista Psicologia USP, 20(2), 157171. doi: http://dx.doi.org/10.1590/ S0103-65642009000200002

Carreira, A. F. (2009b). Sobre a fantasia nos quatro discursos. Revista Cesumar Ciências Humanas e Sociais Aplicadas, 14(1), 125-135.

Feijoo, A. M. L. C. (2010). Tédio e finitude: da filosofia à psicologia. Belo Horizonte, MG: Fundação Guimarães Rosa.

Freud, S. (1996). Romances familiares. In S. Freud, Edição standard brasileira das obras psicológicas completas de Sigmund Freud (J. Salomão, trad., Vol. 9, pp. 219-224). Rio de Janeiro, RJ: Imago. (Trabalho original publicado em 1909)

Huxley, A. (1980). Admirável mundo novo. São Paulo, SP: Abril Cultural.

Jerusalinsky, A. (2010). Psicanálise e desenvolvimento infantil. Porto Alegre: Artes Médicas.

Kupfer, M. C. M., \& Bernardino, L. M. F. (2009). As relaçốes entre construção da imagem corporal, função paterna e hiperatividade: reflexóes a partir da Pesquisa IRDI. Revista Latino Americana de Psicopatologia Fundamental, 12(1), 45-58.

Lacan, J. (1998). O seminário, livro 11: os quatro conceitos fundamentais da psicanálise, 1964. (M. D. Magno, trad.). Rio de Janeiro, RJ: Jorge Zahar.

Lacan, J. (2003). O seminário, livro 9: a identificação, 1961-1962 (I. Correa \& M. Bagno, trads.). Recife, PE: Centro de Estudos Freudianos do Recife. (Publicação não comercial)

Levin, E. (2007). A clínica psicomotora: o corpo na linguagem. Petrópolis, RJ: Vozes.

Pisetta, M.A. M, \& Besset, V.P. (2011) Alienação e separação: elementos para discussão de um caso clínico. Psicologia em Estudo, 16 (2), Junho. Recuperado de http://www.scielo.br/s ciel o.php?pid 
$=$ S141373722011000200015\&script=sci_ arttext

Prestes, S. C. (2005). O sintoma da criança e o trabalho analítico com os pais. Revista Nomear, Rio de Janeiro, out/2005, 5-76.

Quinet, A. A (2000). A descoberta do inconsciente: do desejo ao sintoma. Rio de Janeiro, RJ: Jorge Zahar.

Rosenberg, A. M. S. (Org.) (2002). O lugar dos pais na psicanálise de crianças. São Paulo, SP: Escuta.

Segal, A. M. de R. (2002) O lugar dos pais na psicanálise de crianças. São Paulo: Editora Escuta.

Siquier, M. L., \& Salzberg, B. (2002). A difícil articulação pais-filhos na psicanálise com crianças. In A. M. S. Rosenberg (Org.), O lugar dos pais na psicanálise de crianças (pp. 61-98). Sáo Paulo, SP: Escuta.

Santos, A. C. C., Amorim Neto, T. P., \& Goes, A. C. S. (2013). Ficção científica e o Admirável mundo novo: previsóes concretizadas no atual século e considerações bioéticas. História, Ciências, Saúde, Manguinhos, 20 (2). Recuperado de http:// www.scielo.br/sc ielo.php?script=sci_arttext\&pid=S0104-59702013000200653

Sirelli, N. M. (2010). Alienação e separação: a lógica do significante e do objeto na constituição do sujeito. (Dissertaçáo de mestrado). Departamento de Psicologia, Universidade Federal de São João del Rei, Minas Gerais. Strauss, M. (2000). Separar-se de seus pais. In M. A. C. Ribeiro (Org.), Marraio: a criança e o laço social. Rio de Janeiro, RJ: Formaçóes Clínicas do Campo Lacaniano. Szapiro, A. M., \& Resende, C. M. A. (2010). Juventude: etapa da vida ou estilo de vida? Psicologia \& Sociedade, 22(1), 43-49. doi: http://dx.doi.org/10.1590/ S0102-71822010000100006

\author{
yumi.matsuo@hotmail.com \\ Rua Lavínia, 70 \\ 14091-090 - Ribeirão Preto - SP - Brasil. \\ afcarreira@gmail.com \\ Rua Lavínia, 70 \\ 14091-090 - Ribeirão Preto - SP - Brasil.
}

